\title{
山东临朐新生代地幔捕虏体中的流体熔体包裹体: 软流圈-岩石圈相互作用的信息
}

\author{
刘吉强, 陈立辉 ${ }^{*}$, 倪培* \\ 南京大学地球科学与工程学院, 内生金属矿床成矿机制研究国家重点实验室, 地质流体研究所, 南京 210093 \\ * 联系人, E-mail: chenlh@nju.edu.cn, peini@nju.edu.cn
}

2009-06-11 收稿, 2009-08-24 接受

国家自然科学基金(批准号: 40772035)、国家重点基础研究发展计划(编号: 2006CB403500)和国家自然科学创新群体基金(批准号: 40221301) 资助项目

\begin{abstract}
摘要 橄榄岩捕虏体中的流体(熔体)包裹体是研究地幔流体的最直接样品。应用流体包裹体显 微测温学和激光拉曼技术, 研究了山东临朐乔山地幔橄榄岩捕虏体中的各类流体(熔体)包裹体 (早期富 $\mathrm{CO}_{2}$ 流体包裹体和碳酸盐熔体包裹体, 晚期富 $\mathrm{CO}_{2}$ 流体包裹体和硅酸盐熔体包裹体). 其中早期富 $\mathrm{CO}_{2}$ 流体包裹体多为高密度纯 $\mathrm{CO}_{2}$ 流体包裹体, 部分含有石墨, $\mathrm{CO}, \mathrm{N}_{2}$, 菱镁矿等 多种杂质. 两期流体包裹体的最小捕获压力分别为 $1.42 \mathrm{GPa}$ 和 $0.80 \mathrm{GPa}$. 由于碳酸盐熔体包裹 体的寄主矿物主要是斜方辉石, 据此推测碳酸盐熔体的形成可能与 $\mathrm{CO}_{2}$ 流体和橄榄石、单斜辉 石之间的反应有关. 富 $\mathrm{CO}_{2}$ 流体包裹体中杂质组分的多样性说明橄榄岩曾经经历与流体/熔体 灌入有关的氧化还原反应. 乔山地幔捕虏体的流体(熔体)包裹体证据说明该区陆下岩石圈地幔 曾经被软流圈来源的富 $\mathrm{CO}_{2}$ 流体/熔体所改造.
\end{abstract}

关键词

地幔流体

碳酸盐熔体

流体包裹体

地幔捕虏体

华北克拉通
地幔流体不仅影响着地幔中矿物相的稳定性, 还影响着地幔的流变特征, 控制着橄榄岩的部分熔 融行为 ${ }^{[1,2]}$. 地幔橄榄岩捕虏体中的流体包裹体可以 提供关于地幔流体性质、物理化学条件的重要信息, 是研究地幔流体最直接的途径 ${ }^{[3]}$.

华北克拉通东部在显生宙经历了大规模的岩石 圈转变(或减薄), 中生代以来该地区广泛的壳-幔相 互作用和岩石圈-软流圈相互作用被认为与该过程有 关 ${ }^{[4 ~ 9]}$. 其中位于郯庐断裂附近的新生代碱性玄武岩 中的橄榄岩捕虏体具有较饱满的成分特征, 代表新 生的岩石圈地幔 ${ }^{[9]}$. 由于岩石圈地幔介于地壳和软流 圈地幔之间, 因此, 来自岩石圈地幔的橄榄岩捕虏体 有可能记录着参与壳-幔相互作用和岩石圈-软流圈 相互作用的流体和(或)熔体的信息. 激光拉曼原位分
析 $^{[10,11]}$ 和分步加热气体质谱分析 ${ }^{[12 \sim 17]}$ 结果显示, 中 国东部(包括华北克拉通)地幔捕虏体中的流体包裹 体与世界其他地区的地幔橄榄岩捕虏体中的流体包 裹体一样, 主要由 $\mathrm{CO}_{2}$ 组成, 并含有少量的 $\mathrm{H}_{2} \mathrm{O}, \mathrm{CO}$, $\mathrm{H}_{2}, \mathrm{CH}_{4}, \mathrm{H}_{2} \mathrm{~S}$ 等组分; $\mathrm{C}, \mathrm{O}$ 和稀有气体同位素组成表 明, 这些地幔流体来自软流圈地幔, 可能含有再循环 地壳物质的信息 ${ }^{[12,15,17]}$. 但是, 中国东部地幔流体的 研究还很有限, 尤其是地幔捕虏体中流体成分特征 与岩石圈演化之间的关系还需要进行深人的探讨. 本文对山东临朐乔山的饱满型地幔捕虏体中的流体 (熔体)包裹体进行了详细的岩相学、显微测温学和激 光拉曼分析, 以期获取包裹体所代表的地幔流体的 化学成分, 了解不同类型包裹体的成因及其可能的 相互关系，探讨地幔流体的成分特征与华北克拉通 
岩石圈演化过程之间的可能联系.

\section{1 地质背景和样品描述}

华北克拉通是世界上最古老的太古代克拉通之 一, 位于秦岭-大别-苏鲁超高压带和中亚造山带等显 生宙造山带之间. 南北重力梯度带和郯庐断裂带是 穿越其中的两个关键的南北向构造带. 地幔捕虏体 证据表明, 南北重力梯度带以东地区在显生宙发生 了岩石圈地幔的巨量减薄, 其中郯庐断裂位于岩石 圈减薄的中心 ${ }^{[7,18]}$.

本文的研究区位于郯庐断裂山东段——沂沭断 裂带西侧的昌乐一临朐新生代火山断陷盆地内. 在中 新世盆地内主要发育有两期碱性玄武质岩浆活动, 分别发生在 21.7 15.8 Ma(牛山组)和 14.3 10.6 Ma(尧 山组 $)^{[19]}$. 火山岩中除含有大量地幔橄榄岩捕虏体外, 还发育有大量歪长石、辉石、钛磁铁矿巨晶. 对该地 区的地幔橄榄岩捕虏体的岩石地球化学和同位素研 究显示, 该地区陆下岩石圈地幔主要为新生的岩石 圈地幔 ${ }^{[20,21]}$. 张宏福等人 ${ }^{[22]}$ 在该地区新生代玄武岩 中发现了大量的辉石捕虏晶, 辉石捕虏晶中含有大 量与寄主岩无关的硅酸盐熔体包裹体, 他们认为这 些辉石捕虏晶来自底侵辉石岩, 可能与该区中生代 的壳幔相互作用有关.

本文研究的地幔橄榄岩捕虏体均采自尧山组的 乔山火山口, 地理坐标为 $36^{\circ} 33^{\prime} 23^{\prime \prime} \mathrm{N}, 118^{\circ} 47^{\prime} 45^{\prime \prime} \mathrm{E}$ (采样点见图 1). 地幔橄榄岩捕虏体主要为二辉橄榄 岩, 并有少量方辉橄榄岩, 多为原变粒结构、镶嵌粒 状结构及残碎斑结构. 乔山橄榄岩捕虏体常含黑色 的辉石脉, 在手标本上与寄主玄武岩较难区分. 这种 辉石脉主要由黑色的单斜辉石组成, 辉石中常含有 各种岩浆成因的金属氧化物, 说明这种辉石岩脉可 能与寄主岩浆的反应或结晶有关. 本文在岩石薄片 观察的基础上, 选择没有辉石脉的捕虏体进行包裹 体薄片制备.

\section{2 流体包裹体岩相学特征}

从采集的数十个乔山捕虏体中选出 7 个新鲜样 品制备包裏体片, 从中挑选出包裹体发育丰富的两 个样品进行包裹体测试研究. 根据镜下观察、显微测 温学和激光拉曼光谱分析, 乔山地幔岩捕虏体中的 流体包裏体可以分为两期 4 类: 早期富 $\mathrm{CO}_{2}$ 流体包裹 体和早期碳酸盐熔体包裹体, 晚期熔体包裏体和晚
期富 $\mathrm{CO}_{2}$ 流体包裹体. 本文中的早期包裹体是指随 机(或孤立)分布的包裹体和晶内愈合裂隙中的包裹 体，晚期包裹体是指发育在后期穿晶裂隙内的包裹 体. 下面对各类包裹体分别进行描述.

早期富 $\mathrm{CO}_{2}$ 流体包裹体在两种辉石和橄榄石中 都有发育, 室温时多为单相(液相)(图 2(a) (d)), 有时 为两相, 另一相为气相(图 2(e))或固相(图 2(f)). 它们 在晶内随机分布, 或分布在晶内愈合裂隙(图 2(a))或 矿物边缘生长环带上 (图 2(c)), 呈球形(图 2(a) 和 (b))、椭球形(图 2(f))、管状(图 2(e))或负晶形(图 2(d)) 包裹体直径在 1 20 $\mu \mathrm{m}$ 之间.

早期碳酸盐熔体包裹体与早期富 $\mathrm{CO}_{2}$ 流体包裹 体共生(图 2(g)), 在正交偏光下具有典型的极高双折 射, 呈球形 (或液滴状)随机成群分布在辉石颗粒中, 这种发育方式表明它们现在虽然是碳酸盐矿物, 但 在捕获时最初为碳酸盐熔体 ${ }^{[23]}$. 碳酸盐熔体包裹体 有时被晚期流体包裹体切穿(图 2(g)).

晚期熔体包裹体多发育在橄榄石中, 辉石中也 有少量发育, 室温下为多相(或两相), 由玻璃质熔体 $(\mathrm{Gl}) \pm$ 子晶 $(\mathrm{Dm}) \pm$ 液相 $\mathrm{CO}_{2}(\mathrm{~L}) \pm$ 气相 $\mathrm{CO}_{2}(\mathrm{~V})$ 组成(图 2(h)), 沿矿物间的穿晶裂隙成群或串状分布(图 2(i)). 包裹体 形态不规则, 呈串状、树枝状、长管状、椭圆状发育, 大 小在 $10 \sim 50 \mu \mathrm{m}$ 之间.

晚期流体包裹体在橄榄石和辉石中都有发育, 室温下以暗色气/液单相或两相存在(图 2(h)), 常与晚 期熔体包裹体共存在切穿矿物颗粒的愈合裂隙内, 有时发育在早期流体包裹体周围的微小愈合裂隙中 (图 2(j)), 可能是由早期流体包裹体破裂并释放出的 流体形成的. 包裹体形状发育不规则, 呈蠕虫状、管 状、椭圆状等，大小多在 1 20 $\mu \mathrm{m}$ 之间.

\section{3 分析方法}

包裹体实验均在南京大学内生金属矿床成矿机 制研究国家重点实验室完成. 在岩相学观察的基础 上，选取各类流体包裹体进行显微测温分析，获得包 裹体的相变温度, 再根据相变温度确定包裹体中流 体的成分和捕获压力 ${ }^{[24,25]}$. 测试所用仪器为 Linkam THMS 600 型冷热台, 测定温度范围为 $-196 \sim 600^{\circ} \mathrm{C}$. 在 $<0^{\circ} \mathrm{C}$ 和 $0 \sim 40{ }^{\circ} \mathrm{C}$ 范围, 测试精度分别为 $\pm 0.2^{\circ} \mathrm{C}$ 和 $\pm 1.0^{\circ} \mathrm{C}$. 最后, 根据测温数据, 选择适当的状态方程, 使用 Flincor 程序 ${ }^{[27]}$ 来计算每个包裹体密度, 并获得 每组包裹体中的最高密度包裏体和最低密度包裹体 


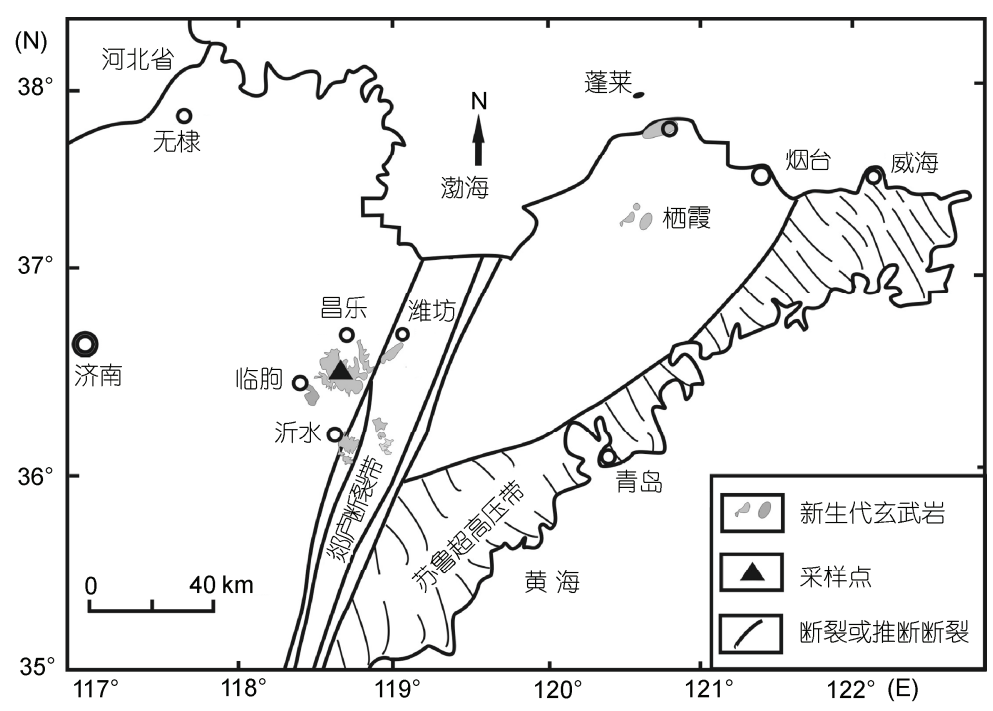

图 1 样品采集点位置示意图 据罗丹等人 ${ }^{[27]}$ 修改

的等容线.

对与流体包裹体共生的晚期多相熔体包裹体进 行了高温均一化实验, 实验所用仪器是配有 LEICA 光学显微镜的 Linkam TS1500 型高温热台, 温度测定 范围为 $25 \sim 1500^{\circ} \mathrm{C}$. 在 $\leqslant 600^{\circ} \mathrm{C}, 600 \sim 1000^{\circ} \mathrm{C}$ 和 $1000 \sim$ $1500^{\circ} \mathrm{C}$ 的不同温度区间, 精度分别为 $\pm 2^{\circ} \mathrm{C}, \pm 5^{\circ} \mathrm{C}$ 和 $\pm 8^{\circ} \mathrm{C}$.

选择代表性包裹体进行激光拉曼光谱测试来分 析包裹体气、液相和包裹体内矿物成分. 实验仪器为 英国 Renishaw 公司 RM2000 型激光拉曼探针. 实验 条件如下: 温度 $25^{\circ} \mathrm{C}, \mathrm{Ar}^{+}$激光器 (514 nm), 风冷, 狭 缝宽 $50 \mu \mathrm{m}$, 光栅 1800 , 积分时间 30 60 s, 扫描次数 两次. 利用气体的拉曼特征峰面积值和相应气体的 拉曼量化因子 ${ }^{[28]}$ 计算出流体包裹体中挥发分的摩尔 相对百分含量.

\section{4 结果}

\section{1 包裹体显微测温学}

(i ) 低温显微测温. 对富 $\mathrm{CO}_{2}$ 流体包裹体进行 了低温显微测温, 冷冻后的包裹体在加热回温过程 中出现两次相转变: 一次是三相点温度 $\left(-56.6{ }^{\circ} \mathrm{C}\right)$ 附 近 $\mathrm{CO}_{2}$ 固体的熔化消失, 另一个是均一温度时 $\mathrm{CO}_{2}$ 气相或液相消失. 显微测温结果见图 3 和表 1.

早期 $\mathrm{CO}_{2}$ 流体包裹体的熔点温度 $\left(T_{\mathrm{m}}\right)$ 在-61.1 $-56.6^{\circ} \mathrm{C}$ 之间(图3(a)), 均一温度 $\left(T_{\mathrm{h}}\right.$ ) 分布在-49.2 $29.6^{\circ} \mathrm{C}$
之间; 而晚期 $\mathrm{CO}_{2}$ 流体包裹体的熔点温度 $\left(T_{\mathrm{m}}\right)$ 在 $-60.3 \sim-56.6^{\circ} \mathrm{C}$ 之间, 均一温度 $\left(T_{\mathrm{h}}\right)$ 在 $-9.8 \sim 30.5^{\circ} \mathrm{C}$ 之间 (表 1). 早期流体包裹体 $T_{\mathrm{m}}$ 的范围要比晚期流体包裏 体广. 在 $T_{\mathrm{h}}$ 频率直方图中, 早期流体包裹体的均一 温度明显分为两个区间: $<-40{ }^{\circ} \mathrm{C}$ 和 $>-20^{\circ} \mathrm{C}$ (图 3(b)), 其中高温区间刚好与晚期包裹体的均一温度区间一 致. 两期包裹体对应计算得到的 $\mathrm{CO}_{2}$ 密度分别为 0.66 1.15 和 $0.22 \sim 0.98 \mathrm{~g} / \mathrm{cm}^{3}$.

部分包裹体 $\mathrm{CO}_{2}$ 熔点温度 $\left(-61.1 \sim-56.6^{\circ} \mathrm{C}\right)$ 较之 纯 $\mathrm{CO}_{2}$ 三相点温度 $\left(-56.6^{\circ} \mathrm{C}\right)$ 偏低, 该现象说明包裹体 内除含有 $\mathrm{CO}_{2}$ 之外, 还含有三相点温度低于 $-56.6^{\circ} \mathrm{C}$ 的 组分, 如 $\mathrm{H}_{2} \mathrm{~S}, \mathrm{~N}_{2}, \mathrm{CO}$ 等气体. 这在我们的激光拉曼光 谱测试中得到了进一步确认.

(ii) 高温均一化实验. 对晚期多相熔体包裹体 的高温均一化实验显示, 熔体包裹体在 $600^{\circ} \mathrm{C}$ 开始熔 融, 大部分子晶在 $900 \sim 1100^{\circ} \mathrm{C}$ 开始熔融. 当温度达 到 $1150 \sim 1250^{\circ} \mathrm{C}$ 时, 气泡和子矿物消失, 熔体包裹体 达到完全均一. 由于熔体包裹体的均一温度 $\left(T_{\mathrm{h}}\right)$ 可以 近似认为是其捕获温度 ${ }^{25,29]}$, 因此我们认为晚期熔 体包裹体的形成温度在 $1150 \sim 1250^{\circ} \mathrm{C}$ 之间.

\section{2 激光拉曼光谱}

分别对各类流体包裹体、碳酸盐熔体包裹体进行 了激光拉曼光谱测试. 结果显示, 乔山橄榄岩捕虏体 中的流体包裹体主要为纯 $\mathrm{CO}_{2}$ 包裹体, 并含有少量 

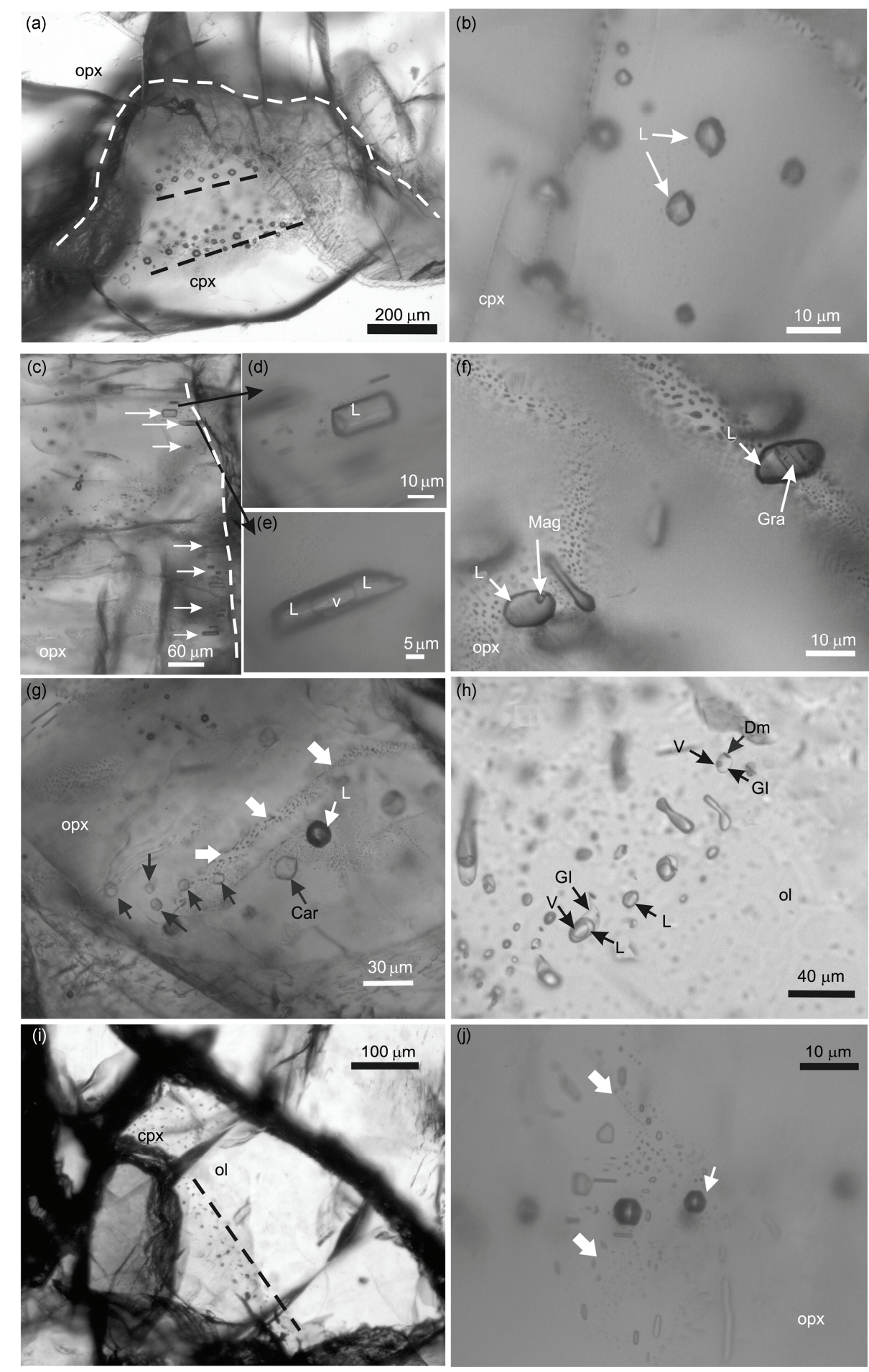

图 2 辉石和橄榄石中流体和熔体包裹体的显微照片

(a) 发育在单斜辉石晶体内愈合裂隙中的早期富 $\mathrm{CO}_{2}$ 流体包裹体(黑色虚线为愈合裂隙的走向, 白色虚线为矿物边界); (b) 高密度纯 $\mathrm{CO}_{2}$ 流体 包裹体; (c) 斜方辉石中沿矿物颗粒边缘生长环带(白色箭头所指)分布的早期流体包裹体; (d)和(e) 分别是(c)中黑色箭头所指的单相、两相 $\mathrm{N}_{2}-\mathrm{CO}-\mathrm{CO}_{2}$ 流体包裹体的放大图; (f) 斜方辉石矿物中同一区域内发育有 $\mathrm{C}$ (石墨) $-\mathrm{CO}^{-} \mathrm{CO}_{2}$ 包裹体和 $\mathrm{MgCO}_{3}$ (菱铎矿) $-\mathrm{CO}_{2}$ 包裹体; $(\mathrm{g})$ 早期 $\mathrm{CO}_{2}$ 流体包裹体(白色窄箭头所指)与碳酸盐熔体包裹体(黑色箭头所指)共生(白色宽箭头所指的是晚期沿愈合裂隙分布的流体包裹体); (h) 橄榄石 矿物颗粒边缘成群分布的晚期流体包裹体和熔体包裹体; (i) 穿晶裂隙内的晚期流体/熔体包裹体(黑色虚线指愈合裂隙边界痕迹); (j) 早期流体

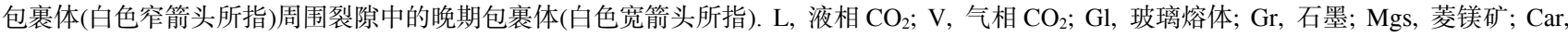
碳酸盐熔体; Dm, 子晶; opx, 斜方辉石; cpx, 单斜辉石; ol, 橄榄石 

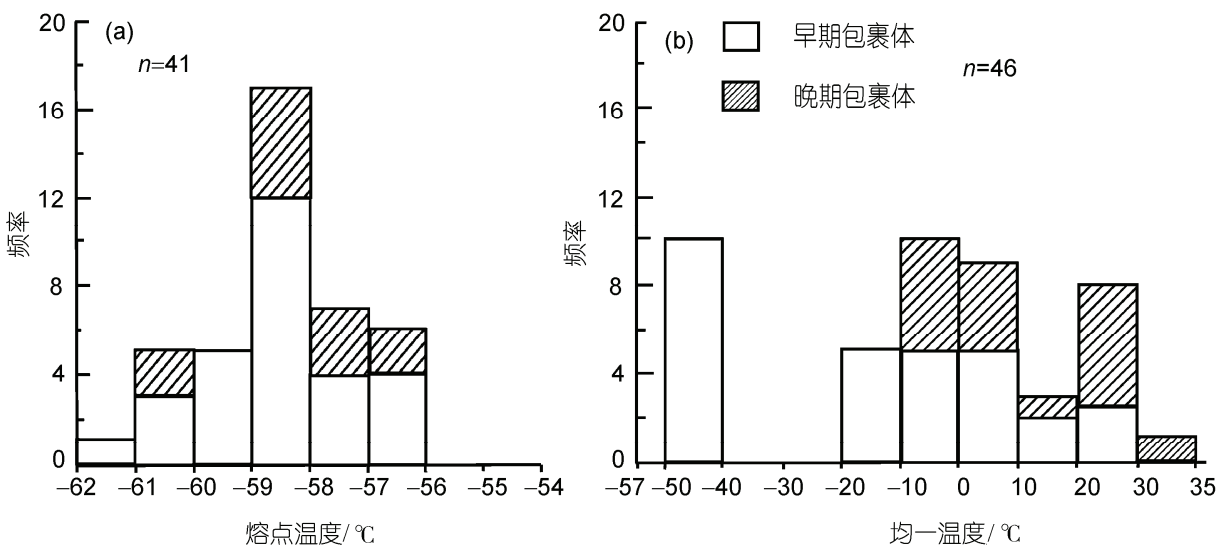

图 3 早期和晚期富 $\mathrm{CO}_{2}$ 包裹体的 $\mathrm{CO}_{2}$ 固体熔点温度 $\left(T_{\mathrm{m}}\right)$ 和均一温度 $\left(T_{\mathrm{h}}\right)$ 频率分布直方图

(a) $\mathrm{CO}_{2}$ 包裹体的固体的熔化温度-频率分布直方图; (b) $\mathrm{CO}_{2}$ 包裹体的均一温度-频率分布直方图

表 1 包裹体显微测温数据

\begin{tabular}{|c|c|c|c|c|c|c|c|}
\hline 包裹体类型 & 寄主矿物和产状 & $\begin{array}{l}\text { 室温下包裹 } \\
\text { 体相组合 }\end{array}$ & $T_{\mathrm{m}}{ }^{\mathrm{a})} /{ }^{\circ} \mathrm{C}$ & $T_{\mathrm{h}}{ }^{\mathrm{b}} /{ }^{\circ} \mathrm{C}$ & $\begin{array}{c}\rho^{\mathrm{c})} / \\
\mathrm{g} \cdot \mathrm{cm}^{-3}\end{array}$ & $T^{\mathrm{d})} /{ }^{\circ} \mathrm{C}$ & $P^{\mathrm{e})} / \mathrm{GPa}$ \\
\hline $\begin{array}{c}\text { 早期流体包裹 } \\
\text { 体 }\left(30^{\mathrm{f})}\right)\end{array}$ & $\begin{array}{c}\text { 橄榄石、辉石中孤立、 } \\
\text { 随机分布 }\end{array}$ & 多为单相 & $-61.1 \sim-56.6$ & $-49.2 \sim 29.6$ & $0.66 \sim 1.15$ & & $0.29 \sim 1.42$ \\
\hline $\begin{array}{c}\text { 晚期流体包裹 } \\
\text { 体(16) }\end{array}$ & $\begin{array}{c}\text { 橄榄石、辉石中沿穿 } \\
\text { 晶裂隙分布 }\end{array}$ & 单相或两相 & $-60.3 \sim-56.6$ & $-9.8 \sim 30.5$ & $0.22 \sim 0.98$ & $1150 \sim 1250$ & $0.07 \sim 0.80$ \\
\hline $\begin{array}{c}\text { 晚期熔体包裹 } \\
\text { 体(12) }\end{array}$ & $\begin{array}{c}\text { 橄榄石、辉石中沿穿 } \\
\text { 晶裂隙分布 }\end{array}$ & 多相或两相 & - & $1150 \sim 1250^{\mathrm{g})}$ & - & $1150 \sim 1250$ & $\geqslant 0.80$ \\
\hline
\end{tabular}

a) $\mathrm{CO}_{2}$ 包裹体的熔点温度; b) 均一温度; c) 包裹体内流体密度; d) 流体与矿物达到平衡的温度; e) 利用等容线法 ${ }^{[24,25,32]}$ 估算的流体捕获 压力; f) 括弧内为包裏体测试个数; g) 熔体包裏体内气泡或子晶消失的温度

含杂质的富 $\mathrm{CO}_{2}$ 包裹体, 杂质成分主要为 $\mathrm{CO}, \mathrm{N}_{2}$ 和 $\mathrm{H}_{2} \mathrm{~S}$, 这与其熔点温度低于 $-56.6^{\circ} \mathrm{C}$ 的结果一致. 另外, 在与碳酸盐包裹体共生的 $\mathrm{CO}-\mathrm{CO}_{2}$ 流体包裹体中发 现了石墨晶体. 其中, 早期流体包裹体除了高密度纯 $\mathrm{CO}_{2}$ 包裹体外, 含杂质的包裹体可进一步分为 $\mathrm{N}_{2}-\mathrm{CO}$ $\mathrm{CO}_{2}$ 组合、 $\mathrm{C}$ (石墨) $-\mathrm{CO}-\mathrm{CO}_{2}$ 组合、 $(\mathrm{Mg}, \mathrm{Ca}) \mathrm{CO}_{3}$ (碳酸 盐) $-\mathrm{CO}_{2}$ 组合. 晚期流体包裹体主要是纯 $\mathrm{CO}_{2}$ 包裹体, 有时含少量 $\mathrm{H}_{2} \mathrm{~S}$ 杂质. 以下对各类流体 (熔体)的激光 拉曼光谱特征分别进行描述.

( i ) $\mathrm{N}_{2}-\mathrm{CO}-\mathrm{CO}_{2}$ 流体包裹体. 此类包裹体的拉 曼光谱中, 除在 1388 和 $1285 \mathrm{~cm}^{-1}$ 处有强烈的 $\mathrm{CO}_{2}$ 振动峰外, 还在 $2140 \mathrm{~cm}^{-1}$ 处检测到明显的 $\mathrm{CO}$ 峰(图 $4\left(\right.$ a)), 在 $2329 \mathrm{~cm}^{-1}$ 位置处检测到 $\mathrm{N}_{2}$ 峰. 空气中大量 的 $\mathrm{N}_{2}$ 可能影响对流体包裹体中 $\mathrm{N}_{2}$ 的测定, 采用 Andersen 等人 ${ }^{[30]}$ 的方法直接测试空气中的 $\mathrm{N}_{2}$, 结果 显示空气中的 $\mathrm{N}_{2}$ 信号远远低于激光拉曼探针在此条 件下的检测限, 因此拉曼光谱中 $\mathrm{N}_{2}$ 的信号来自于流 体包裹体. 显微测温学结果显示, 这些包裹体与共生
的纯 $\mathrm{CO}_{2}$ 流体包裹体一样具有较高的密度.

激光拉曼定量分析 (表 2)显示, 这类包裹体含有 $\sim 3.5 \mathrm{~mol} \%$ 的 $\mathrm{CO}$ 和 $1.6 \mathrm{~mol} \%$ 的 $\mathrm{N}_{2}$. 个别包裹体内的 $\mathrm{CO}_{2}$ 含量仅为 $95.8 \mathrm{~mol} \%$, 这与 $\mathrm{CO}_{2}$ 固相熔点降低到 $-61.1^{\circ} \mathrm{C}$ 一致.

(ii ) $\mathrm{C}$ (石墨) $-\mathrm{CO}-\mathrm{CO}_{2}$ 流体包裹体. 此类流体包 裹体不仅有 $\mathrm{CO}$ 峰 $\left(2139 \mathrm{~cm}^{-1}\right)$, 而且还有 $1590 \mathrm{~cm}^{-1}$ 振动峰(图 4(b)), 这表明存在高温石墨. 石墨的信号 不可能是包裹体外的物质引起的, 因为当把激光束 移到周围的主矿物时，石墨的信号消失. 同时，石墨

表 2 单个含 CO 流体包裹体的激光拉曼定量分析数据 ${ }^{\text {a) }}$

\begin{tabular}{|c|c|c|c|c|}
\hline \multirow{2}{*}{ 包裏体编号 } & \multicolumn{3}{|c|}{ 组成摩尔百分数 $/ \mathrm{mol} \%$} & \multirow{2}{*}{$\begin{array}{c}T_{\mathrm{m}} /{ }^{\circ} \mathrm{C} \\
\mathrm{S}+\mathrm{V} \rightarrow \mathrm{L}+\mathrm{V}\end{array}$} \\
\hline & $\mathrm{CO}$ & $\mathrm{N}_{2}$ & $\mathrm{CO}_{2}$ & \\
\hline QS02X0102a2 & 3.2 & - & 96.8 & -58.4 \\
\hline QS02X0101c2 & 3.4 & - & 96.6 & -59.1 \\
\hline QS02X0101a3 & 3.5 & - & 96.5 & -58.7 \\
\hline QS0102 & 1.6 & 0.7 & 97.7 & -60.1 \\
\hline QS0104 & 2.6 & 1.6 & 95.8 & -61.8 \\
\hline
\end{tabular}

a) 数据为相对百分含量 

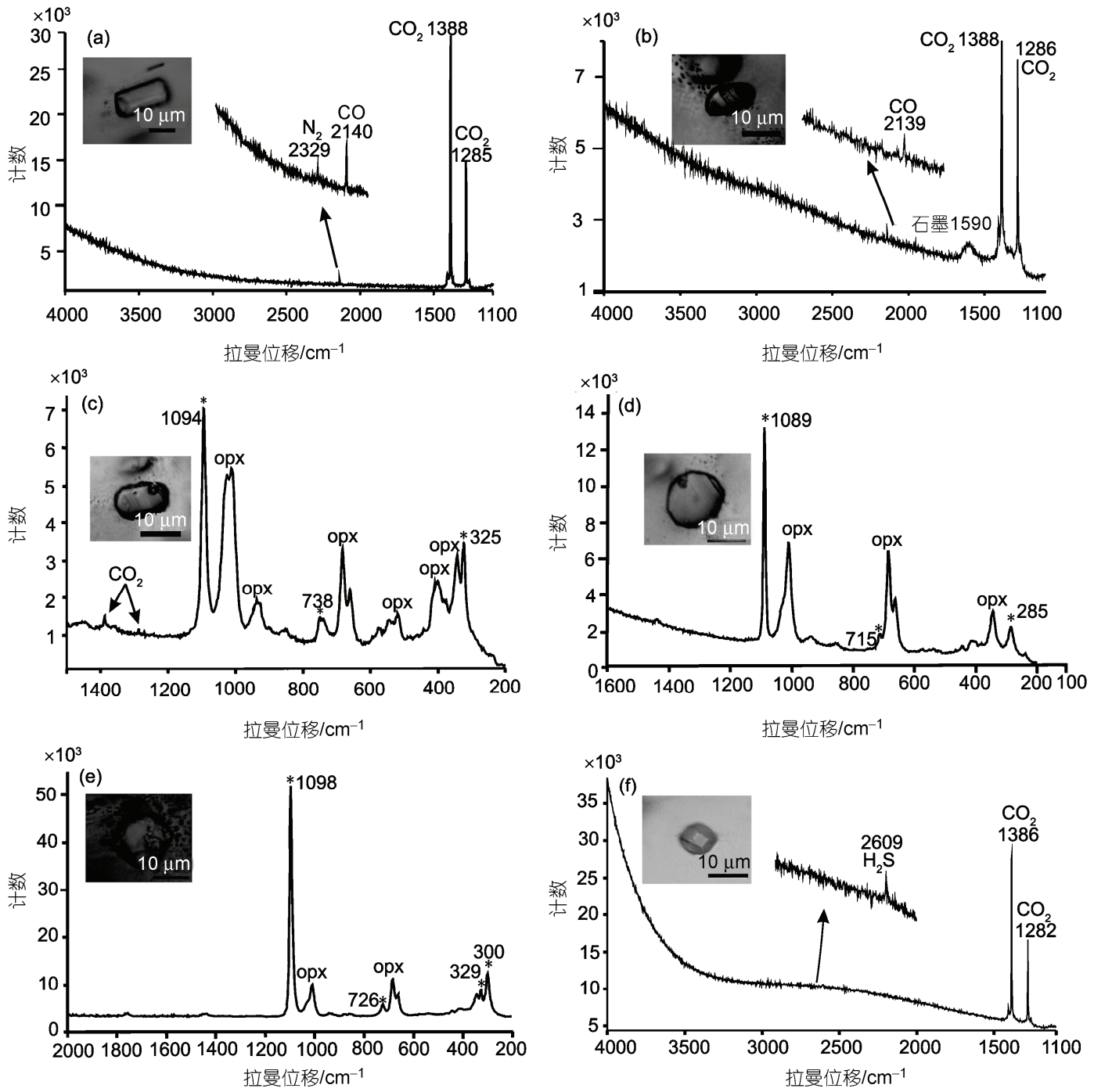

图 4 流体/熔体包裹体的激光拉曼光谱

(a) 斜方辉石中早期 $\mathrm{N}_{2}-\mathrm{CO}_{-}-\mathrm{CO}_{2}$ 流体包裏体的激光拉曼光谱; (b) $\mathrm{C}$ (石墨) - $\mathrm{CO}^{-} \mathrm{CO}_{2}$ 包裹体的激光拉曼光谱; (c) $\mathrm{CO}_{2}$ 流体包裏体内菱镁矿的激光 拉曼光谱; (d) 流体包裹体内含 $\mathrm{Mg}$ 碳酸钙矿物的激光拉曼光谱; (e) 白云质碳酸盐熔体包裹体的激光拉曼光谱; (f) 单斜辉石中含 $\mathrm{H}_{2} \mathrm{~S}-\mathrm{CO}_{2}$ 流体 包裹体的激光拉曼光谱; 星号代表碳酸盐矿物的拉曼峰

信号也不可能来自样品上表面，因为样品未喷碳，而 且分析仪器的聚焦能力在垂直方向上的分辨率可以 达 $10 \mu \mathrm{m}$ 深度.

结晶完好的石墨晶体只在 $1580 \mathrm{~cm}^{-1}$ 附近有一个 非常强的拉曼峰，如果石墨晶体有一定程度的结晶 无序性, 那么会在 $1350 \mathrm{~cm}^{-1}$ 附近有第二个振动峰 ${ }^{[28]}$. 唯一的 $1590 \mathrm{~cm}^{-1}$ 峰位(图 4(b))说明这种包裹体中所 包含的石墨为高温有序结晶石墨.

(iii) $(\mathrm{Mg}, \mathrm{Ca}) \mathrm{CO}_{3}$ (碳酸盐) $-\mathrm{CO}_{2}$ 流体碳酸盐包裹 体和碳酸盐熔体包裹体. 含碳酸盐流体包裹体和碳 酸盐熔体包裹体多产于斜方辉石中. 如图 2(f)所示,
图中左下方含碳酸盐矿物的流体包裹体与 $\mathrm{C}($ 石 墨)-CO- $\mathrm{CO}_{2}$ 流体包裹体(图 2(f)右上角)共生, 它的拉 曼光谱(图 4(c))在 $1094,738,325 \mathrm{~cm}^{-1}$ 处的振动峰与 菱镁矿的标准拉曼振动峰位相符, 因此图 2(f)中包裹 体内的球形矿物为菱镁矿. $738 \mathrm{~cm}^{-1}$ 振动峰较宽的半 高宽可能是由于微米尺度大小的菱镁矿结晶程度低, 或是受到主矿物斜方辉石在 $736 \mathrm{~cm}^{-1}$ 附近 Si-O-Si 键 振动峰 ${ }^{[11]}$ 的影响. 另外, 我们根据在 $1089,715,285$ $\mathrm{cm}^{-1}$ 处的拉曼特征峰在富 $\mathrm{CO}_{2}$ 流体包裹体中鉴定出 含 $\mathrm{Mg}$ 碳酸钲(图 4(d)). 单个碳酸盐熔体包裹体(图 $2(\mathrm{~g})$ ) 在 $1098,726,300 \mathrm{~cm}^{-1}$ 处的拉曼峰(图 4(e))是白 
云石的特征峰, 其在 $329 \mathrm{~cm}^{-1}$ 处的峰可能是熔体中 含有少量菱镁矿成分造成的. 因此, 早期富 $\mathrm{CO}_{2}$ 流体 包裏体中发现的碳酸盐矿物为菱镁矿和含 $\mathrm{Mg}$ 碳酸 钻, 而碳酸盐熔体包裹体的原始成分介于白云石和 菱镁矿之间。

(iv) 晚期 $\mathrm{H}_{2} \mathrm{~S}-\mathrm{CO}_{2}$ 流体和熔体包裹体. 拉曼光 谱分析结果显示, 晚期包裹体流体中绝大多数为纯 $\mathrm{CO}_{2}$, 少量流体中除了 $\mathrm{CO}_{2}$ 外还存在少量的 $\mathrm{H}_{2} \mathrm{~S}$ (图 4 (f)), 这与显微测温学结果相符. 岩相学观察和高温 测温学结果显示, 晚期熔体包裹体可能是与晚期流 体同时形成的，对此本文不做详细讨论.

综合结果显示, 早期包裹体主要是高密度 $\mathrm{CO}_{2}$ 流体包裏体和碳酸盐熔体包裹体, 其中 $\mathrm{CO}_{2}$ 流体中 含有 $\mathrm{N}_{2}, \mathrm{CO}$, 石墨和碳酸盐等杂质. 晚期包裹体主要 是硅酸盐熔体和中低密度的 $\mathrm{CO}_{2}$ 流体, 杂质仅有 $\mathrm{H}_{2} \mathrm{~S}$. 根据晚期熔体包裹体的均一温度推测, 两期流体包 裹体的捕获温度在 $1150 \sim 1250^{\circ} \mathrm{C}$ 之间.

\section{5 讨论}

\section{1 富 $\mathrm{CO}_{2}$ 流体捕获的温压限定}

假定与晚期 $\mathrm{CO}_{2}$ 包裹体共生的熔体包裹体的均 一温度代表两类 $\mathrm{CO}_{2}$ 包裹体的捕获温度, 即 $1200^{\circ} \mathrm{C}$ (取平均值), 根据等容线法 ${ }^{[3,32]}$ 利用流体包裹体的密 度计算出两类包裹体内部压力值分别为 $0.29 \sim 1.42 \mathrm{GPa}$ 和 0.07 0.80 $\mathrm{GPa}$ (表 1). 由于地幔捕虏体中的流体包 裹体捕获后期可能在上升过程中受到不同过程(如包 裹体的泄漏或爆裂、流体与寄主矿物的反应等)的影 响 $^{[3]}$, 因此根据一个流体包裹体组合测到的最大密度 计算的压力值仅代表流体捕获的最小压力. 早期高 密度 $\mathrm{CO}_{2}$ 流体捕获的最小压力为 $1.42 \mathrm{GPa}$ (对应深度 为 $47 \mathrm{~km}$ ), 晚期 $\mathrm{CO}_{2}$ 流体包裹体形成的最小压力为 $0.80 \mathrm{GPa}$ (对应深度为 $26 \mathrm{~km}$ ). 这说明早期流体包裹 体捕获于岩石圈地幔，而晚期流体的捕获深度相对 较浅(比如莫霍面附近).

\section{2 流体包毫体中碳酸盐矿物的成因}

地幔岩中 $\mathrm{CO}_{2}$ 流体包裏体内的碳酸盐常被解释 为 $\mathrm{CO}_{2}$ 流体与寄主矿物间相互反应而形成的一种次 生矿物组合 ${ }^{[33]}$. 这种反应生成的矿物与寄主矿物的 成分有关, 如菱镁矿只在斜方辉石中发育, 白云石 (或富 $\mathrm{Mg}$ 碳酸钙)只在单斜辉石中发育. 在乔山橄榄 岩中, 斜方辉石中的流体包裹体不仅有菱镁矿 (图 4(c)), 还有富 $M g$ 碳酸钙(图 4(d)), 在单斜辉石中的 流体包裹体中也有这两种碳酸盐. 因此, 流体包裹体 中的碳酸盐矿物不是 $\mathrm{CO}_{2}$ 流体与寄主矿物间相互反 应的产物，而可能是包裹体形成时被捕获的.

\section{3 碳酸盐包裹体的成因}

地幔橄榄岩中的碳酸盐包裹体往往以白云质碳 酸盐或菱镁矿成分为主，通常认为这些包裹体代表 地幔条件下已存的碳酸盐熔体 ${ }^{[3]}$. 乔山样品中碳酸盐 包裹体的球形(液滴状)(图 2(g))发育特征显示其最初 捕获的为碳酸盐液体，与其同期形成的高密度流体 包裹体说明其来源深度在 $47 \mathrm{~km}$ 以下. 碳酸盐熔体常 被认为是地幔交代作用的重要介质 ${ }^{[34-38]}$. 但是其易 于和地幔围岩反应 ${ }^{\left[{ }^{[3]}\right.}$ 或发生脱碳作用 ${ }^{[39]}$ 而很难在地 幔橄榄岩捕虏体中保存, 因此关于地幔碳酸盐质熔 体的成因存在许多不同观点: (1) 含碳酸盐橄榄岩的 部分熔融 ${ }^{[34]}$; (2) 地幔中富硅碳酸盐熔体的不混溶作 用 ${ }^{[40,41]}$; (3) 硅酸盐-碳酸盐熔体/流体与橄榄岩之间 的交代作用 ${ }^{[42]}$. 虽然晚期 $\mathrm{CO}_{2}$ 流体包裹体与硅酸盐 熔体包裹体共生，但早期流体包裹体中未发现有硅 酸盐熔体的发育, 说明早期未发生不混溶作用. 另外, 交代作用形成的富硅碳酸盐熔体/流体以富碱为特 征 $^{[42]}$, 与之相反, 乔山碳酸盐熔体以 $\mathrm{Ca}, \mathrm{Mg}$ 碳酸盐 为主. 含碳酸盐橄榄岩的部分熔融时会伴随富 $\mathrm{Al}, \mathrm{Na}$ 质玻璃的发育 ${ }^{[34]}$, 而这种成分的玻璃却未在乔山橄 榄岩中发现, 因此, 乔山地幔中的碳酸盐熔体也可能 不是由含碳酸盐橄榄岩部分熔融产生的. 我们注意 到早期碳酸盐熔体包裹体多在斜方辉石中发育, 说 明碳酸盐熔体在斜方辉石结晶之前或结晶时就存在. 在上地幔条件下，与碳酸盐熔体和斜方辉石同时相 关的主要反应有 ${ }^{[43,44]}$ :

$2 \mathrm{Mg}_{2} \mathrm{SiO}_{4}$ (橄榄石) $+\mathrm{CaMgSi}_{2} \mathrm{O}_{6}$ (单斜辉石 $)+2 \mathrm{CO}_{2}=$ $4 \mathrm{Mg}_{2} \mathrm{Si}_{2} \mathrm{O}_{6}$ (斜方辉石) $+\mathrm{CaMg}\left(\mathrm{CO}_{3}\right)_{2}$ (碳酸盐),

$2 \mathrm{Mg}_{2} \mathrm{SiO}_{4}$ (橄榄石) $+2 \mathrm{CO}_{2}=\mathrm{Mg}_{2} \mathrm{Si}_{2} \mathrm{O}_{6}$ (斜方辉石) + $2 \mathrm{MgCO}_{3}$ (碳酸盐).

当 $\mathrm{CO}_{2}$ 过剩时, 反应向生成斜方辉石和碳酸盐熔体 的方向进行. 部分早期富 $\mathrm{CO}_{2}$ 流体包裏体沿斜方辉 石生长环带发育(图 2(c)) 的现象说明 $\mathrm{CO}_{2}$ 参与了与斜 方辉石生长有关的反应. 在这些反应中由于斜方辉 石和碳酸盐都在反应的一侧, 所以碳酸盐是斜方辉 石生长过程中捕获的，这就解释了富 $\mathrm{CO}_{2}$ 流体包裹 
体中碳酸盐与寄主矿物成分解耦的现象.

浅部地幔中的流体主要由 $\mathrm{CO}_{2}$ 组成, 这些 $\mathrm{CO}_{2}$ 主要是来自上地幔深部的碳酸盐熔体/矿物的脱碳作 用 ${ }^{[3]}$. 乔山橄榄岩中的部分斜方辉石同时含有早期富 $\mathrm{CO}_{2}$ 流体包裹体和碳酸盐熔体包裹体的现象说明, 由 于 $\mathrm{CO}_{2}$ 过剩, 该区陆下岩石圈地幔中发生了消耗橄 榄石(和单斜辉石)生成斜方辉石和碳酸盐熔体的反 应. 如果这一推断正确的话, 那么就意味着这些新生 饱满的尖晶石橄榄岩曾经经历软流圈来源的流体改 造, 这一反应机制可能对华北克拉通中生代岩石圈 巨量减薄具有一定的指示意义. 少量单斜辉石中碳 酸盐熔体包裹体的发育可以解释为反应(1)向左发生.

\section{4 复杂流体组分的成因及意义}

世界范围内地幔捕虏体中的流体包裹体主要由 $\mathrm{CO}_{2}$ 组成 ${ }^{[3]}$, 虽然在这些富 $\mathrm{CO}_{2}$ 流体包裹体中发现了 很多种类的杂质, 但很少有多种杂质在单个样品中 共存的现象. 相对而言, 乔山地幔捕虏体中的早期流 体组分比较复杂, 碳元素在这些流体包裹体中以零 价(石墨)、二价 $(\mathrm{CO})$ 和四价 $\left(\mathrm{CO}_{2}\right.$ 和碳酸盐) 3 种价态共 存. 来自古生代金伯利岩中金刚石的流体包裹体证 据表明 ${ }^{[45,46]}$, 华北克拉通古生代岩石圈地幔中除了 $\mathrm{CO}_{2}$ 外, 还含有较多还原性流体组分, 如 $\mathrm{CH}_{4}, \mathrm{H}_{2} \mathrm{~S}$, $\mathrm{NH}_{3}, \mathrm{H}_{2}$ 等, 说明古老的岩石圈地幔具有较低的氧逸 度. 与古生代金刚石中流体包裹体的成分相比, 乔山 地幔流体包裹体的成分 (如 $\mathrm{C}-\mathrm{CO}-\mathrm{CO}_{2}$ ) 所反应的氧逸 度明显增高, 暗示该区岩石圈地幔在显生宙发生大 规模减薄的同时, 岩石圈地幔中流体的氧逸度也发 生了明显的改变. 这一过程可以通过以下方式实现:

$$
\begin{gathered}
\mathrm{CH}_{4}+2 \mathrm{CO}_{2}=2 \mathrm{H}_{2} \mathrm{O}+\mathrm{C}+2 \mathrm{CO}, \\
\mathrm{C}+\mathrm{CO}_{2}=2 \mathrm{CO} .
\end{gathered}
$$

华北地区发育有大量具有 OIB 地球化学特征的 新生代碱性玄武岩 (一般认为来源于地幔软流圈), 氧 逸度在 FMQ 附近 ${ }^{[47]}$. 软流圈地幔偏高的电导率说明 软流圈地幔中含有一定量的碳酸盐熔体 ${ }^{[48]}$. 在岩石 圈减薄过程中, 必然伴随着软流圈地幔顶界的上升. 其中的碳酸盐将减压分解生成 $\mathrm{CO}_{2}{ }^{[39]}$. 因此在岩石 圈减薄背景下软流圈来源的流体以 $\mathrm{CO}_{2}$ 为主, 这种 高氧逸度流体的上升必然与岩石圈地幔中氧逸度相 对偏低的流体反应生成 $\mathrm{C}$ 和 $\mathrm{CO}$ 等杂质组分.

因此, 乔山橄榄岩捕虏体中早期碳酸盐熔体包 裹体的发育和早期富 $\mathrm{CO}_{2}$ 流体包裹体组分的复杂性 都是软流圈来源的流体改造岩石圈地幔的结果, 是 岩石圈减薄背景下软流圈-岩石圈相互作用的反映. 晚期流体(熔体)由于捕获压力较低, 可能是橄榄岩捕 虏体被寄主岩浆捕获后生成的, 是寄主岩浆上升过 程中析出的流体(熔体) ${ }^{[49]}$.

\section{6 结论}

山东乔山的二辉橄榄岩捕虏体中存在两期流体 (熔体)包裹体: 早期主要为高密度 $\mathrm{CO}_{2}$ 流体包裹体和 少量碳酸盐熔体包裹体, 晚期主要为低密度 $\mathrm{CO}_{2}$ 流 体包裹体和少量硅酸盐熔体包裹体. 根据显微测温学 数据推测, 两期 $\mathrm{CO}_{2}$ 流体包裏体的捕获温度为 1150 $1250^{\circ} \mathrm{C}$, 捕获最小压力分别为 1.42 和 $0.80 \mathrm{GPa}$.

早期碳酸盐熔体包裹体与斜方辉石的发育关系 表明, 碳酸盐熔体和斜方辉石可能是由富 $\mathrm{CO}_{2}$ 流体 与地幔中其他硅酸盐矿物的反应形成的. 早期富 $\mathrm{CO}_{2}$ 流体包裹体中杂质成分的复杂性亦说明寄主矿物的 成因可能与富 $\mathrm{CO}_{2}$ 流体的反应有关. 总之, 乔山地幔 捕虏体中流体/熔体包裹体的成分特征是该区近期软 流圈-岩石圈相互作用的结果.

\section{参考文献}

1 Dasgupta R, Hirschmann M M. Melting in the Earth's deep upper mantle caused by carbon dioxide. Nature, 2006, 440: 659-662

2 Mierdel K, Keppler H, Smyth J R, et al. Water solubility in aluminous orthopyroxene and the origin of Earth's asthenosphere. Science, 2007, 315: 364-368

3 Andersen T, Neumann E R. Fluid inclusions in mantle xenoliths. Lithos, 2001, 55: 301-320

4 Zhang H F, Sun M, Zhou X H, et al. Mesozoic lithosphere destruction beneath the North China Craton: Evidence from major-, trace-element and $\mathrm{Sr}-\mathrm{Nd}-\mathrm{Pb}$ isotope studies of Fangcheng basalts. Contrib Mineral Petrol, 2002, 144: 241-253

5 周新华. 中国东部中、新生代岩石圈转型与减薄研究若干问题. 地学前缘, 2006, 13: 50-64 
6 Menzies M A, Fan W M, Zhang M. Palaeozoic and Cenozoic lithoprobes and the loss of $>120$ km of Archaean lithosphere, Sino-Korean craton, China. In: Prichard H M, Alabaster T, Harris N B W, eds. Magmatic Processes and Plate Tectonics. Geol Soc London Spec Pub, 1993, 76: $71-81$

$7 \mathrm{Xu} \mathrm{Y} \mathrm{G.} \mathrm{Thermo-tectonic} \mathrm{destruction} \mathrm{of} \mathrm{the} \mathrm{Archaean} \mathrm{lithospheric} \mathrm{keel} \mathrm{beneath} \mathrm{the} \mathrm{Sino-Korean} \mathrm{Craton} \mathrm{in} \mathrm{China:} \mathrm{Evidence,} \mathrm{timing} \mathrm{and}$ mechanism. Phys Chem Earth Part A-Solid Earth Geod, 2001, 26: 747-757

$8 \mathrm{Xu} \mathrm{Y} \mathrm{G,} \mathrm{Ma} \mathrm{J} \mathrm{L,} \mathrm{Frey} \mathrm{F} \mathrm{A,} \mathrm{et} \mathrm{al.} \mathrm{Role} \mathrm{of} \mathrm{lithosphere-asthenosphere} \mathrm{interaction} \mathrm{in} \mathrm{the} \mathrm{genesis} \mathrm{of} \mathrm{Quaternary} \mathrm{alkali} \mathrm{and} \mathrm{tholeiitic} \mathrm{basalts}$ from Datong, western North China Craton. Chem Geol, 2005, 224: 247-271

9 Zheng J P, Griffin W L, O'Reilly S Y, et al. Mineral chemistry of peridotites from Paleozoic, Mesozoic and Cenozoic lithosphere: Constraints on mantle evolution beneath eastern China. J Petrol, 2006, 47: 2233-2256

10 Xia L Q, Xia Z C, Xu X Y. Fluids and melts in the upper mantle. Acta Geol Sin, 1999, 73: 330-340

11 㚞祺诚, 刘若新, 彭礼贵. 我国东南沿海地区地幔流体性质及其意义. 科学通报, 1992, 27: 1584一 1587

12 Zhang M J, Hu P Q, Niu Y L, et al. Chemical and stable isotopic constraints on the nature and origin of volatiles in the sub-continental lithospheric mantle beneath eastern China. Lithos, 2007, 96: 55-66

13 樊祺诚, 刘若新, 林卓然, 等. 中国东部地幔 $\mathrm{CO}_{2}$ 流体包裹体的碳同位素初步研究. 地球化学, 1996, 25: 264一-269

14 刘刚, 王先涁, 文启涁. 张家口大麻坪碱性玄武岩内深源岩包体流体的碳同位素组成. 科学通报, 1998, 43: 2098一 2101

15 Yang X Y, Zheng Y F, Liu D, et al. Chemical and carbon isotope composition of fluid inclusions on peridotite xenoliths and eclogite from eastern China: Geodynamic implication. Phs Chem Earth, 2001, 26: 705-718

16 马锦龙, 陶明信, 叶先仁. 山东临沭地区幔源矿物中的流体包和稀有气体地球化学研究. 中国科学 D 辑: 地球科学, 2005 , 35 : 1019 $-1027$

17 李延河, 李金城, 宋鹤壁, 等. 中国东部新生代玄武岩中幔源包体和高压巨晶的氦同位素研究. 中国科学 D辑: 地球科学, 2001, 31: $641-647$

18 Zheng J P, Griffin W L, O'Reilly S Y, et al. Mechanism and timing of lithospheric modification and replacement beneath the eastern North China Craton: Peridotitic xenoliths from the 100 Ma Fuxin basalts and a regional synthesis. Geochim Cosmochim Acta, 2007, 71: $5203-5225$

19 刘若新, 陈文寄, 孙建中, 等. 中国新生代火山岩年代学与地球化学. 北京: 地震出版社, 1992.1一43

20 Zheng J P, O'Reilly S Y, Griffin W L, et al. Nature and evolution of Cenozoic lithospheric mantle beneath Shandong peninsula, Sino-Korean craton, eastern China. Int Geol Rev, 1998, 40: 471-499

21 Zheng J P, Sun M, Zhou M F, et al. Trace elemental and PGE geochemical constraints of Mesozoic and Cenozoic peridotitic xenoliths on lithospheric evolution of the North China Craton. Geochim Cosmochim Acta, 2005, 69: 3401-3418

22 张宏福, Nakamura E, 张瑾, 等. 山东临朐新生代玄武岩携带的单斜辉石晶体中玻璃质熔体包裹体. 科学通报, 2006, 51: 1558一 1564

23 Frezzotti M L, Peccerillo A. Diamond-bearing COHS fluids in the mantle beneath Hawaii. Earth Planet Sci Lett, 2007, 262: 273-283

24 Hollister L S, Crawford M L. Short course in fluid inclusions: Applications to petrology. In: Mineralogical Association of Canada Short Course Handbook, Vol.6, 1981. 304

25 Roedder E. Fluid Inclusions. In: Ribbe P H. Mineralogical Society of America. Washington D C: Book Crafters Inc, 1984. 644

26 Brown P E. FLINCOR: A microcomputer program for the reduction and investigation of fluid-inclusion data. Am Mineral, 1989, 74: 1390 $-1393$

27 罗丹, 陈立辉, 曾罡. 陆内强碱性火山岩的成因: 以山东无棣大山霞石岩为例. 岩石学报, 2009, 25: 311一 319

28 Burke E A J. Raman microspectrometry of fluid inclusions. Lithos, 2001, 55: 139-158

29 Roedder E. Geobarometry of ultramafic xenoliths from Loihi Seamount, Hawaii, on the basis of $\mathrm{CO}_{2}$ inclusions in olivine. Earth Planet Sci Lett, 1983, 66: 369-379

30 Andersen T, Burke E A J, Neumann E R. Nitrogen-rich fluid in the upper mantle: Fluid inclusions in spinel dunite from Lanzarote, Canary Islands. Contrib Mineral Petrol, 1995, 120: 20-28

31 Huang E, Chen C H, Huang T, et al. Raman spectroscopic characteristics of Mg-Fe-Ca pyroxenes. Am Mineral, 2000, 85: 473-479

32 刘吉强, 倪培, 丁俊英, 等. 江苏六合地区上地幔流体 P-T 条件的限定: 流体包裹体证据. 岩石学报, 2007, 23: 2069一 2078

33 Frezzotti M L, Andersen T, Neumann E R, et al. Carbonatite melt- $\mathrm{CO}_{2}$ fluid inclusions in mantle xenoliths from Tenerife, Canary Islands: A story of trapping, immiscibility and fluid-rock interaction in the upper mantle. Lithos, 2002, 64: 77-96

34 Ionov D A, Dupuy C, O'Reilly S Y, et al. Carbonated peridotite xenoliths from Spitsbergen: Implications for trace element signature of mantle carbonate metasomatism. Earth Planet Sci Lett, 1993, 119: 283-297

35 Yaxley G M, Green D H, Kamenetsky V S. Carbonatite metasomatism in the southeastern Australian lithosphere. J Petrol, 1998, 39: 1917 $-1930$

36 Green D H, Wallace M E. Mantle metasomatism by ephemeral carbonatite melts. Nature, 1988, 336: 459-462

37 Hauri E H, Shimizu N, Dieu J J, et al. Evidence for hotspot-related carbonatite metasomatism in the oceanic upper mantle. Nature, 1993, 
365: $221-227$

38 Kamenetsky M B, Sobolev A V, Kamenetsky V S, et al. Kimberlite melts rich in alkali chlorides and carbonates: A potent metasomatic agent in the mantle. Geology, 2004, 32: 845-848

39 Canil D. Experimental study bearing on the absence of carbonate in mantle-derived xenoliths. Geology, 1990, 18: 1011-1013

40 Schiano P, Clocchiatti R, Shimizu N, et al. Cogenetic silica-rich and carbonate-rich melts trapped in mantle minerals in Kergulen ultramafic xenoliths: Implications for metasomatism in the oceanic upper mantle. Earth Planet Sci Lett, 1994, 123: 167-178

41 Frezzotti M L, Touret J L R, Lustenhouwer W J, et al. Melt and fluid inclusions in dunite xenoliths from La Gomera, Canary Islands: Tracking the mantle metasomatic fluids. Eur J Mineral, 1994, 6: 805-817

42 Schrauder M, Navon O. Hydrous and carbonatitic mantle fluids in fibrous diamonds from Jwaneng, Botswana. Geochim Cosmochim Acta, 1994, 58: 761-771

43 Yaxley G M, Green D H. Experimental reconstruction of sodic dolomitic carbonatite melts from metasomatised lithosphere. Contrib Mineral Petrol, 1996, 124: 359-369

44 Yaxley G M, Crawford A J. Green D H. Evidence for carbonatite metasomatism in spinel peridotite xenoliths from western Victoria, Australia. Earth Planet Sci Lett, 1991, 107: 305-317

45 郑建平. 金刚石中流体包裹体的研究. 科学通报, 1994, 39: 253-253

46 杜乐天. 地幔流体与软流层(体)地球化学. 北京: 地质出版社, 1996. 466

47 张毅刚，鄂莫岗. 中国东部新生代玄武岩及其地幔包体的氧逸度. 岩石学报, 1994, 10: 161-170

48 Gaillard F, Malki M, Iacono-Marziano G, et al. Carbonatite melts and electrical conductivity in the asthenosphere. Science, 2008, 322: $1363-1365$

49 Ertan I E, Leeman W P. Fluid inclusions in mantle and lower crustal xenoliths from the Simcoe volcanic field, Washington. Chem Geol, 1999, 154: 83-95

- 动 态・

\section{利用三齿吡啶艮全或半包夹硫酸根离子}

阴离子在生命科学、医药、催化及环境化学等领域具 有重要作用，对阴离子的识别、检测和分离研究越来越引 起人们的关注. 但相对阳离子而言, 阴离子配位化学的认 识还处于起步阶段. 中国科学院兰州化学物理研究所羰基 合成与选择氧化国家重点实验室吴彪研究组与合作者, 设 计了系列含脲基团的阴离子受体，其中三齿吡啶脲可通过 氢键饱和状态的模式 2:1 包夹硫酸根离子. 他们又通过调 节阳离子尺寸及形成氢键的能力并利用二级配位效应, 实
现了受体与硫酸根的 $1: 1$ 结合. 阴离子竞争实验证明硫酸 根可选择性析出. 他们并应用固体堆积方式和氢键作用方 式对阴离子配位模式给出了合理解释，对于深刻理解硫酸 根离子的结合模式和选择性分离具有重要的意义. 相关研 究论文发表在 2009年 11 月 2 日 Inorganic Chemistry, 48(21): 9959-10476 上.

(信息来源：科学技术部《基础科学研究快报》)

\section{碳纳米管/聚二炔纳米复合纤维的简易合成方法}

有色材料如聚二炔可以响应温度、 $\mathrm{pH}$ 、化学信号或压 力等广泛的环境刺激而改变颜色, 已被用于开发传感设备. 复旦大学聚合物分子工程教育部重点实验室彭慧胜研究组 与合作者, 发明了一种合成碳纳米管/聚二炔纳米复合纤 维的简易方法. 新合成的纤维可以迅速而可逆地应答电流 变化, 产生的颜色变化可以被裸眼观察到. 这些复合纤维
还可响应其他刺激并发生颜色变化，如可在很小拉伸导致 的应力诱导下产生色差. 这种电色纳米复合纤维在传感领 域将有广泛的应用. 相关研究论文发表在 2009 年 11 月 Nature Nanotechnology, 4(11): 38-741 上.

(信息来源：科学技术部《基础科学研究快报》) 